\title{
An Integrated Framework for Examining Innovation Alignment in Organizations
}

\author{
Ebru Dilan* and Mehmet N. Aydin ${ }^{\dagger}$ \\ Kadir Has University, Kadir Has Caddesi \\ Cibali, Istanbul, TR 34083, Turkey \\ *ebru.dilan@khas.edu.tr \\ ${ }^{\dagger}$ mehmet.aydin@khas.edu.tr
}

Received 5 December 2017

Accepted 26 November 2018

Published 28 December 2018

\begin{abstract}
Innovation has been promoted as a panacea to solve the long-standing problem of how organizations deal with complexities associated with uncertainty and instability in ever changing environments. information systems (IS) research focusing on innovation has adopted several perspectives to reveal a rich context in which the innovation surfaces as a phenomenon. Examination of a rich context may contribute to a better understanding of an extent to which uncertainty and instability can affect or be affected by innovation strategies that require various innovation efforts in an organization. In this regard, one of the most critical issues is to ensure that these innovation efforts can achieve a successful outcome via their strategic and structural alignment. In this research, we propose an integrated framework that addresses an innovation alignment issue by employing three high-level notions (strategic dimensions, structural characteristics, strategizing acts). The integrated framework has been used rigorously in two cases for an explorative purpose. Our interpretation of the evidence suggests that strategizing act, as a high-level notion has an explanatory power to articulate the associations between strategic dimensions and structural characteristics. Among other findings, we have observed that the closed, incremental and process-oriented innovation strategy is particularly relevant to the corporate level whereas radical, product-oriented, and partially open innovation strategy is associated with a more exclusive innovation structure.
\end{abstract}

Keywords: Digital innovation; corporate innovation; innovation strategy; complexity; instability; uncertainty; innovation alignment; ambidexterity.

\section{Introduction}

In rapidly changing dynamic environments, innovation has been recognized as crucial for organizations to survive and compete [Milling and Stumpfe (2000)]. However, embedding innovation into existing organizational structures, routines, ways of thinking and working is an enduring problem for which organizations are searching for solutions [Tidd et al. (2005)]. With new technologies and digitalization, the issue becomes more challenging. Innovation practice occurs in a context that is unique to an organization. There is no one-size-fits all. In this regard, one can see 
that innovation practice is manifested at two levels in an organization: at the unit and corporate levels. The innovation contexts of the two levels have received increased attention from both researchers and practitioners. In essence, innovation practice is concerned with how organizations deal with strategic and operational changes to achieve agility, competitiveness, leadership and high-performance capabilities for delivering new products, process or even new business models [Yoo et al. (2012); Schilling (2015)].

Utilizing digital technologies and managing digital innovation are complex challenges for firms at various levels (i.e. product/service, individual, unit, organization, platform, network, and ecosystem). Building up a capacity to oversee and govern innovation practice, which is surrounded by a complex relations mosaic inside and outside the organization, is demanding [Tidd et al. (2005)]. The challenges derive from remarkable complexity. Two key features of the complexity involve the rapid pace of digital innovation processes [Yoo et al. (2010)] and generativity of digital technology [Avital and Te'Eni (2009); Yoo et al. (2012)]. Digitizing innovation incorporates processes and outcomes (product/services) shaping and being shaped by the other [Bailey et al. (2012); Lee and Berente (2012)]. The process of creating products and services is extremely altered by the adoption of digital technologies [Yoo et al. (2012)].

Innovation has been promoted as a panacea to solve the long-standing problem of how organizations deal with complexities associated with uncertainty and instability in ever changing environments. information systems (IS) research focusing on innovation has adopted several perspectives to reveal a rich context in which innovation surfaces as a phenomenon. A rich context may refer to better understanding of the extent to which uncertainty and instability can have an effect or be affected by innovation strategies that require various innovation efforts in an organization. One of the persistent issues that affect the very success of innovation endeavors in organizations is the alignment of various innovation practices that are contextualized at unit and organization levels. Indeed, different strategies and environments necessitate different structural configurations and alignments in organizations. Thus, one needs to understand those strategic dimensions characterizing innovation practices and their alignments at corporate and unit levels. As shall be elaborated in the literature review, the existing research on innovation appears to pay attention to innovation alignment through a number of different perspectives. One needs to consider broader and integrated perspectives when examining innovation alignment.

A prime way to understand the extent to which innovation practices are aligned is to determine the strategic dimensions characterizing innovation practices at corporate and unit levels and to address the innovation alignment issue using an integrative approach. To do this, we take into account three strategic dimensions: the type of innovation (product, process, business model, and marketing), the degree of innovation (radical versus incremental), and governance (firm/closed, open) emphasizing a communication aspect. We have not applied a hypothesis driven approach to trace the relationship between these three strategic dimensions. 
Another fundamental way to address innovation alignment is to examine organizational arrangements for various aligned or non-aligned practices. To do so, one needs to examine the structural characteristics (arrangement) of innovation practices at corporate and unit levels. For this purpose, we employed structural characteristics such as innovation practices at corporate (CI) and unit levels (DI), a common framework, processes, tools/techniques.

One needs to further elaborate the associations between strategic (distinguishing aspects) dimensions and structural characteristics. We contend that various degrees of unknown and/or unpredictable environments mediate the association between strategic dimensions and structural characteristics. We conceptualized such mediation as strategizing acts. Thus, we explore the associations between strategic dimensions and structural characteristics based on strategizing acts in virtue of degrees of uncertainty and degrees of instability in the environment [Bessant et al. (2005)].

In this research, we adopted an integrative approach to employ a framework for examining innovation alignment in organizations through an empirical study facilitating descriptive and explorative views for two cases at hand. The contribution of this study is twofold: First, it provides a conceptual articulation for the issue of innovation alignment in organizations, second, it empirically provides rich insights into innovation alignment related to strategic and organizational perspectives.

\section{Theoretical Framework and Literature Review}

In the last decade embracing of innovation as a strategic imperative by businesses in almost every area has attracted the attention of many scholars and professionals. Services in particular have shown noteworthy progress through information technologies-driven improvements especially in rising economies like Turkey [Dursun et al. (2014)]. From operational and strategic points of view one can observe that new openings and risks arise for organizations due to the advances in technologies. Digital innovation as a natural consequence of these advances is characterized by the formation and resultant change in market offerings, business models and processes that accompany digital technology utilization [Nambisan et al. (2017)].

Digital innovation holds three key characteristics distinguishing it from prior technologies: reprogrammability (unlike analog technology), the homogenization of data (mapping of analog signals into binary digits and separating the content from the medium), and the self-referential nature of digital technology (digital innovation requires and uses digital technology) [Yoo et al. (2010)]. These characteristics result in a four layered architecture: devices (physical machinery and logical capability layers), networks (physical transport and logical transmission layers), services (carrying out application functionality), and contents (design issues) [Gao and Iyer (2006); Yoo et al. (2010)]. As these three key characteristics evolve into higher forms, and companies install more sophisticated digital components in their products, the layered architecture extends to layered modular architectures in which a digitized product can be a product and a platform at the same time (due to its dynamic and 
loosely coupled nature). Consequently, innovations emerge freely at any layer without any spillover effects on any of the other layers [Yoo et al. (2010)].

Information systems innovation might be extensively characterized as innovation in the organizational application of information technologies [Swanson (1994)]. Mustonen-Ollila and Lyytinen [2004] studied information system process innovations and classified them into technological (such as new IS functionalities, adoptions of operating systems and programming languages) and administrative innovations (project management methods, new approaches to development interactions and contracting). Technological innovation embraced two sub-categories; tool innovations and core technologies innovations. Administrative innovation contained management innovation and descriptive innovation sub-categories. Similarly, Aydin and Dilan [2016] examined the drivers and implications of information systems process innovations in financial company and suggested that the differentiation between process and product innovation was not clear, since the exemplary case project demonstrated the product innovation on one hand (a new product/service was launched on to the market) and process innovation on the other hand (operations touching the end-customer were changed and significant improvements were observed).

Considering the structural aspects, innovation does not fit the organizations' traditional structure. It needs to be addressed at a strategic level beyond a functional level and requires strategic commitment [Cottam et al. (2001)]. There are a number of aspects shaping how organizations handle innovation and take it into account as they get organized for it such as innovation type, degree and governance. We elaborate on these aspects in the following sections.

The type of (focus on) innovation such as product, process, business model, and marketing is of interest to many researchers. As mentioned as an example in the preceding paragraph, there are various innovation types (classifications and labels) in different frameworks and models. Knight [1967] proposed types of product/service, production-process, organizational structure and people innovation. Utterback [1971] proposed dual categorization of product and process innovation. These types were extended and enriched with additional new classifications and new labels as follows; ancillary [Damanpour (1987)], technical, administrative [Bantel and Jackson (1989); Damanpour (1991)] radical, incremental [Cooper (1998)], organizational [Boer and During (2001); Trott (2005)], new products, new services, new ways of organizing, new methods of production, opening new markets, new sources of supply [Johannessen et al. (2001)], business systems [Hovgaard and Hansen (2004)], management, production, commercial/marketing [Trott (2005)], service [Oke et al. (2007)], position and paradigm [Bessant and Tidd (2007); Francis and Bessant (2005)], hybrid or product/service systems [Velamuri et al. (2008)].

Likewise, Matthyssens et al. [2006] determined enterprise process innovation as a broadly perceived source of competitive advantage. Duening [2007] argued that the ingredients of methods (such as re-engineering, supply chain management, continuous quality improvement, six sigma)] are well known, and suggested how to blend these components into a customized recipe for a particular organization is the question. 
In Francis and Bessant [2005]'s model, from the perspective of change achieved with innovation, product innovation refers to the changes in the offered products or services, process innovation corresponds to the changes in the way in which products or services are generated and transferred, position innovation refers to the changes in the context in which products or services are offered and introduced, and paradigm innovation corresponds to the changes in the mental models framing the organizations' actions (shifts in markets or perceptions). Rowley et al. [2011] mapped Francis and Bessant [2005]'s model to previously described innovation types which are given in parentheses in the following sentence. Their study summarized the types of innovation as follows: product innovation (product, service, hybrid), process innovation (technical, production, organizational, administrative, management, people and business system), position innovation (commercial/marketing and business system — overlaps with process innovation), and paradigm innovation (no prior focus).

Cooper's [1998] three-dimensional unifying model categorized the types of innovation as product, process, technical, administrative, radical and incremental. The radical/incremental dual classification is based on the degree of innovation [Rowley et al. (2011)]. Oke et al. [2007] and Ritala and Hurmelinna Laukkanen [2013] extended product innovation into radical innovation and incremental innovation as well. Incremental and radical innovations differ in nature. Incremental innovation is a gradual, continuous add-on to an existing concept, and it is evolutionary and narrowly focused. On the other hand, radical innovation is a fundamental change [Dewar and Dutton (1986)], which is revolutionary and broadly focused. Whereas minor alterations to products/services are concerned with incremental innovation, significant departure from existing abilities in the organization and establishing the ground for totally new products/services is concerned with radical innovation [Garcia and Calantone (2002)]. Henderson and Clark [1990] added two further descriptions to the typical radical/incremental duality by categorizing innovations along two dimensions: impact of innovation on components (reinforced vs. overturned) and impact of innovation on the linkages between components (changed vs. unchanged). Innovation changing solely a technology's core design concepts was defined as modular innovation, whereas innovation changing solely the relationships between them was defined as architectural innovation. Two dimensions constituted four definitions of types respectively; incremental (reinforced, unchanged), modular (overturned, unchanged), architectural (reinforced, changed), and radical (overturned, changed) [Henderson and Clark (1990)].

Svahn et al. [2017] addressed four competing and systemically interrelated concerns that incumbent firms encounter when they embrace digital innovation: innovation capabilities (existing versus requisite), focus (product versus process), collaboration (internal versus external) and governance (control versus flexible), through their presentation of the Volvo Car Corporation case. The study underlined these four concerns' singular orbits, collective rise, and versatile integration. The authors suggested that "a sustainable design vision is at the heart of managerial intervention", while Barrett et al. [2012] delineated digital innovation as an 
emergent process wherein uncertain results cannot be prevented by managerial intervention.

Nylén and Holmström [2015] presented a managerial framework with a holistic view of digital innovation dealing with uncertainty across three aspects: products (user experience and value proposition), environment (digital evolution scanning) and organizational properties (skills and improvisation). They contended that instead of attempting to impose a focal control on digital innovation processes, firms should instead tackle complexity through conjunctional innovation by advancing improvisation (composing and performing concurrently) throughout the organization. Since digital innovation commonly happens across various units, it is essential for firms to build governance mechanisms.

The innovating capability of a firm deriving from the interaction with other firms was introduced as "open innovation" (OI) by Chesbrough [2006]. Firms can adopt OI through one or more of the followings strategies; inbound OI (internal use of external knowledge), outbound OI (external use of internal knowledge), and coupled OI (active collaboration with partners to innovate) [Cheng and Huizingh (2014)]. Considering the breadth (variety of external innovation channels) and depth (the extent to which a firm draws deeply from them) of knowledge search, Saebi and Foss [2015] illustrated a continuum of open innovativeness, differentiating between four types of open business models; market-based innovation strategy (for efficiencycentric open business model), crowd-based innovation strategy (for user-centric open business model), collaborative innovation strategy (for collaborative open business model), and network-based innovation strategy (for open platform business model). Besides, inbound open innovation strategies were linked to the firm performance [Greco et al. (2016)]. To improve the development and market success of radical innovations, actively collaborating with external organizations, adopting a collaborative innovation strategy (entering into collaborative agreements with a few knowledge-intensive partners, ensuring frequent interactions [Saebi and Foss (2015)] or network-based innovation strategy (appropriate when the required knowledge is widely distributed outside a firm's organizational boundaries [Saebi and Foss (2015)] was suggested to the management. On the other hand, to improve the development and market success of incremental innovations, exploring different channels to draw knowledge from external organizations, adopting a crowd-based innovation strategy (knowledge input is sourced from a large number of actors [Saebi and Foss (2015)] was suggested to the management [Greco et al. (2016)].

Campbell and Guttel [2005] examined the firms from knowledge production perspective and developed the "academic firm" concept. These firms focus on maximizing or optimizing knowledge and innovation whereas commercial firms focus on maximizing and optimizing profit.

One can also look at knowledge and innovation in the context of general systems theory. Two main conceptual attributes of systems which are elements and rationale were linked with knowledge clusters (agglomerations of co-specialized, mutually complementary, and reinforcing knowledge assets in the form of knowledge stocks and knowledge flows that exhibit self-organizing learning driven, dynamically adaptive competences and trends) and innovation networks (real and virtual 
infrastructures and infra-technologies that serve to nurture creativity, trigger innovation, and catalyze innovation in a public and/or private domain context) respectively [Carayannis and Campbell (2011)]. Triple helix model of knowledge [Etzkowitz and Leydesdorff (2000)] emphasizing university, industry, and government relationships was extended to "quadruple helix" by involving media-based and culture-based public as well as the civil society [Carayannis and Campbell (2009)] succeeding the introduction of "Mode 3" innovation ecosystem [Carayannis and Campbell (2006)] which is a multilateral (parties and agents involved), multi-nodal (knowledge nodes and knowledge clusters), multimodal (knowledge and innovation mode), and multilevel (spatial/geographic (such as local, national, global), research (such as R\&D, science and technology and R\&D referring innovation), and education) system of systems. Furthermore, "quadruple helix" was extended "quintuple helix" bringing in the perspective of natural environments of society and the economy for knowledge production and the innovation systems [Carayannis and Campbell (2011)].

Through the term of fractals (patterns within patterns) from mathematics, "knowledge fractals" emphasize the continuum-like bottom-up and top-down progress of complexity in knowledge creation, diffusion and use [Carayannis and Campbell (2011)]. Each subcomponent of a knowledge cluster and innovation network can be displayed as a micro-level sub-configuration of knowledge clusters and innovation networks. Meanwhile, one can also move upward [Carayannis and Campbell (2011)].

Felin and Zenger [2014] proposed six distinct governance forms (four open forms, two closed forms). Authority-based hierarchy and consensus-based hierarchy are two closed forms. Markets/contracts, partnership/alliances, contests/platforms and user/communities are four open forms. Their comparison is based on the means that each introduces to three instruments: communication channels for transferring knowledge, incentives for motivating search, and intellectual property rights over solutions and knowledge. These governance forms are corresponded with attributes of solution search and with problems that vary in complexity and the level of hidden knowledge relevant to solving them.

In the information systems domain, traditional software development is losing its power, and platform-based software ecosystems (e.g., iOS, Firefox) are becoming an efficient model for domain actors. Tiwana et al. [2010] underlined the competitive shift towards platform-based ecosystems as a typical consequence of the appearance of software-based platforms and investigated governance at the platform level (Goldilocks Governance Problem) from three perspectives; decision rights (authority and responsibility sharing), control mechanisms (incentives alignment), and proprietary versus shared ownership (stakes sharing).

The governance issue may be addressed at the network level as well. Lyytinen et al. [2016] examined digital product innovation by adopting an innovation network view in which heterogeneity of operant resources (digital convergence) together with distribution of coordination and control via operand resources (digital connectivity) constitute a two dimensional matrix structure, and categorized product innovation networks into four types: project innovation network (centralized, homogeneous), clan innovation network (distributed, homogeneous), federated innovation network 
(centralized, heterogeneous), and anarchic innovation network (distributed, heterogeneous), taking into account their socio-technical nature (ideas, actors, knowhow, tools and technologies) [Tuomi (2002); Van de Ven et al. (1999)]. Defining the dynamics of innovation networks, these innovation researchers have already shifted to -fractal, fluid or wakes- images reflecting nonlinear, distributed, emergent characteristics of digital product innovation rather than earlier technology-push and market-pull models. In addition, Lyytinen et al. [2016] claimed that organizations will inevitably move towards anarchic types of innovation networks if they desire to embrace digital product innovation's full capacity. Utilizing Lyytinen et al. [2016]'s innovation network categorization, Isaksson and Hylving [2017] discussed the effects of different digital product innovation networks within the same organization, observed anarchic action in federated innovation networks in the AutoInc case study and suggested fine-tuning (different dimensions as a continuum) in evaluation of network characteristics rather than two characteristics resulting in four distinct categories (project, clan, federated, anarchic). Networks always communicate a pattern of "co-opetition" [Nalebuff et al. (1996)], reflecting a specific balance of cooperation and competition. Different knowledge and innovation modes (for example linear and non-linear innovation modes linking together universities (mode 1, mode 2, and/or mode 3) with commercial and academic firms) are combined and integrated via coexisting, co-evolving, co-specializing and co-opeting diverse and heterogeneous configurations of knowledge creation, diffusion and use in an emerging fractal knowledge and innovation ecosystem [Carayannis and Campbell (2011)]. Moreover, the researchers developed "knowledge swings" concept linking democracy to knowledge and innovation, considering dominant and non-dominant knowledge modes in a specific context, and pluralism of knowledge modes which exist in parallel, thus co-develop and co-evolve.

Therefore, the significance of connecting with outside communities for firms should not be underestimated. The external stakeholders' role as value co-creators and their engagement are significant factors. Thus, new designs and potential outcomes can be encouraged for generative products through a progressive transformative process [Avital and Te'Eni (2009); Jonsson et al. (2008)].

The aspects elaborated above (innovation type, degree and governance) are strategic dimensions which affect organizational configurations and structural characteristics. Our attention is on the environmental contingencies which mediate the association between these strategic dimensions and structural characteristics, and which require complex decision making in situations of varying degrees of uncertainty and instability.

There is no "one best way" to guarantee successful innovation management, since industries, organizational attributes, markets and technological circumstances vary [Tidd (1997)]. Contingency theory is a well-recognized option which suggests ways to interpret how context alters innovation management. Although the theory has been widely referred to, it has also been criticized for accepting organizational structure as a central concept and underestimating other effects such as managerial preferences, institutional demands [Powell and DiMaggio (1991)] and strategic 
choices [Chandler (1990); Child (1972)]. Following the effects of contingencies on the organization and management of innovation, Tidd [1993] pointed to "strategic degree of freedom" rather than "best practice". The relationships between key environmental contingencies (uncertainty and complexity), type and degree of innovation (product, process, incremental, radical), organizational configurations (structure, processes) and performance (growth, market share) are objects of interest [Tidd (2001)]. Although deciding innovation type and degree definitely is not easy, it is mostly beneficial since distinct types and degrees are linked with various environmental contingencies. As an industry matures, a shift is recommended from product to process innovation and from radical to incremental innovation [Abernathy and Utterback (1978)]. Moreover, approaches for managing radical or disruptive innovation differ from approaches for managing incremental (sustaining) innovation [Tidd et al. (2005)]. The types of innovation (product, process, position, paradigm) can occur in various degrees ranging from incremental to radical. Conjunction of these two dimensions constitutes the potential "innovation space" within which an organization can operate [Tidd et al. (2005)]. "Innovation space" is managed via two dimensions, namely type of innovation (process, product, service) and degree of innovation (incremental, radical, disruptive). Complexity and uncertainty (environmental contingencies) influence the type, degree of innovation, organizational configuration and performance. However, the connection between innovation and performance is not easy to build empirically for reasons such as the fact that, the innovation inputs and outputs relationships are significantly weaker at firm level than at industry level [Tidd (2001)].

Effective innovation process management is associated with "good practice" theme ("steady state" model) which corresponds to mature phase [Abernathy and Utterback (1978)]. As Bessant et al. [2005] noted, while good practices are useful, the existence of many different variables (such as business model innovation, architectural innovation) and the rapid developments in market, technological and political shifts create discontinuity or dislocation. That is, high instability or shift in rules of game and/or high uncertainty or no knowledge leads to the need for new management approaches. Bessant et al. [2005] defined two archetypes to manage steady state and discontinuous innovation applying Greenwood and Hinings's [1993] approach of three key elements; interpretative schema, strategic decision making and operating rules. Steady state and discontinues innovation strategies are represented in two dimensions (degree of uncertainty and degree of instability) and four zones (exploit, uncover, flex, co-evolve). The "exploit" zone corresponds to low uncertainty (clear stage of knowledge, steady state environment) and low instability (stable in terms of rules of game). The "uncover" zone corresponds to high uncertainty (state of knowledge is less clear, new things are needed to find out at exploring around technological or market trajectories) but low instability (stable in terms of rules of game). The "flex" zone corresponds to low uncertainty (high degree of knowledge about shifts or how to find out or respond) but high instability (rules of game change). Lastly, the "co-evolve" zone corresponds to high uncertainty (unknown or unknowable state of knowledge) and high instability (shift in rules of game) [Bessant et al. (2005)]. As uncertainty and instability increase, an organization's 
innovation management operations and experience might not be of help, and a more flexible, open ended, agile and emergent approach which depends on co-evolution of market and technological trajectories, experimentation, fast failure and learning is required [Bessant et al. (2005)]. Different archetypes define different organizational arrangements and leads to ambidexterity [Tushman and O'Reilly (1996)]. Firms operating in various markets, offering various technologies and serving various customers may deal with various types of innovation simultaneously. By structuring ambidextrous organizational designs and gaining dynamic capabilities (through exploratory and exploitative units), organizations can manage incremental and radical innovation concurrently [O'Reilly and Tushman (2008)].

The framework we developed for examining innovation alignment in organizations has three high-level notions; strategic dimensions (type of innovation, degree of innovation, innovation governance), structural characteristics (innovation practices in corporate (CI) and unit levels (DI), common framework, processes, tools/techniques), and strategizing acts (exploit, uncover, flex, evolve) as seen in Table 1. The first high-level notion is used for answering our research questions, starting with the first question as "What strategic dimensions characterize innovation practices at corporate and unit levels?" While operationalizing this notion, we derive three distinguishing dimensions from our empirical data: the focus, degree and governance of innovation. The focus (type of innovation) dimension examines the practices categorically (product, process, business model, market, organizational, etc.) while degree of innovation dimension does this from the extent/range of change perspective (incremental versus radical). The most essential element for governance is actually communication for the purpose of this study. We concentrate on the communication channels for transferring knowledge as the governance instrument. We have not applied a hypothesis driven approach to trace the relationship between these three strategic dimensions. The second high-level notion of this research involves structural characteristics and is concerned with the second research question, which is "What structural characteristics (arrangement) for innovation practices can be used to address an alignment issue in organizations at corporate and unit levels?" The structural characteristics are articulated with the following items; innovating

Table 1. Integrated framework for examining innovation alignment in organizations.

\begin{tabular}{|c|c|c|c|}
\hline High-level notions & Aspects & Specific items adopted & References \\
\hline \multirow[t]{3}{*}{$\begin{array}{l}\text { Strategic } \\
\quad \text { dimensions }\end{array}$} & $\begin{array}{l}\text { Type of (focus on) } \\
\text { innovation }\end{array}$ & $\begin{array}{l}\text { Product, process, business } \\
\text { model, marketing }\end{array}$ & $\begin{array}{l}\text { Francis and Bessant [2005]; } \\
\text { Rowley et al. }[2011]\end{array}$ \\
\hline & Degree of innovation & Radical, incremental & $\begin{array}{l}\text { Ritala and Hurmelinna } \\
\text { Laukkanen [2013] }\end{array}$ \\
\hline & Governance & Closed, open & Felin and Zenger [2014] \\
\hline $\begin{array}{l}\text { Structural } \\
\text { characteristics }\end{array}$ & $\begin{array}{l}\text { Innovation practices } \\
\text { in corporate (CI) and } \\
\text { unit (DI) levels }\end{array}$ & $\begin{array}{l}\text { Organizational structure, } \\
\text { reference model, } \\
\text { processes, } \\
\text { tools/techniques }\end{array}$ & $\begin{array}{l}\text { Chandler [1990]; } \\
\text { Powell and DiMaggio } \\
\text { [1991]; Tidd [1993]; } \\
\text { Nambisan et al. }[2017]\end{array}$ \\
\hline $\begin{array}{l}\text { Strategizing acts } \\
\quad \text { (steady state vs. } \\
\text { discontinuous) }\end{array}$ & $\begin{array}{l}\text { Degree of uncertainty } \\
\text { Degree of instability }\end{array}$ & $\begin{array}{l}\text { Exploit, uncover, } \\
\text { flex, co-evolve }\end{array}$ & $\begin{array}{l}\text { Bessant et al. }[2005] \\
\quad \text { Lazzarotti et al. }[2017]\end{array}$ \\
\hline
\end{tabular}


endeavors in various levels - corporate (CI) and unit (DI)-, innovation practices, reference model, processes, tools and techniques accompanying enterprise idea management systems. Regarding the research questions three and four "What are the associations between structural dimensions and structural characteristics?" and "How do strategizing acts mediate these associations?", we add strategizing acts as the third high-level notion which corresponds to complex systems and decision making in varying degrees of unknown and/or unpredictable environments. As response to questions regarding strategizing acts notion, we adopted Bessant et al.'s [2005] steady state versus discontinuous innovation strategies (exploit, uncover, flex, co-evolve) based on the degree of uncertainty and the degree of instability.

\section{Method}

We adopted the case study research method since it provides a rich context in which to study the phenomenon of interest under investigation [Yin (2013)]. The study was organized in an explorative framework to understand the actual innovation management practice enabled by corporate innovation system program. Other structural characteristics such as innovation endeavors, common framework, processes, tools/ techniques were examined as well. We investigated the strategic dimensions such as type and degree of innovation, and governance in two case organizations (Case Alpha and Case Beta) for a 12-month period (December 2016-December 2017). Case Alpha and Case Beta organizations conduct their innovation efforts on two different levels; corporate level (CI) and unit level (DI). The study is aimed to discover and understand the associations between strategic dimensions and structural characteristics (arrangements) and the mediation of these associations. The organizations' names are not disclosed due to confidentiality reasons.

Two case organizations (Case Alpha and Case Beta) were strategically selected since they have adopted the same innovation framework as a reference point for designing a corporate innovation system at enterprises. Case Alpha is a global service company operating in travel and leisure industry, Case Beta is one of the leading national information and communications technology (ICT) companies in Turkey. As shall be explained later on, the reference innovation framework was adopted as part of the national corporate innovation program. The program which offers a reference framework to all participating organizations, including Case Alpha and Beta, was launched by Turkish Exporters Assembly (Türkiye Ihracatçlar Meclisi) in November 2016. As expected even the same reference innovation framework has been used, designing a corporate innovation system for each organization takes into account organization peculiarities and that leads to an organization-specific innovation process. In two cases, it is worth noticing to identify other kinds of innovation practices which are independent from the adopted framework. This is due to the fact that innovation efforts in two organizations have started before the national program launched. Naturally such efforts were governed in business units. This allows us to examine an extent to which the corporate innovation processes at Case Alpha and Case Beta differ from each other and from other independent innovation practices in business units. It is this independence that raises the alignment issue for 
various innovation endeavors in organizations. Thus, the central questions underpinning this research motivation are as follows:

(i) What strategic dimensions characterize innovation practices at corporate and unit levels?

(ii) What structural characteristics for innovation practices can be used to address an alignment issue in organizations at corporate and unit levels?

(iii) What are the associations between strategic dimensions and structural characteristics?

(iv) How do strategizing acts mediate these associations?

The data was collected by conducting interviews, reviewing the business documents and publicly available data, and internal documents (innovation assessment report, innovation strategy document, technology roadmap) related to the corporate innovation system program at the case organizations. The unit of analysis is innovation endeavors where innovation unfolds and is practiced along with the proposed framework in both cases. In two cases (Case Alpha and Case Beta), we examined the innovation endeavors (called it Digital Innovation (DI), Corporate Innovation), accompanying their attributes, innovation practices, processes, and governance. We conducted interviews with the following roles; the directors of DI units, innovation mentors commissioned to CI units, and specialists of DI units (Appendix A).

\subsection{Case study background}

Turkish Exporters Assembly (TEA) launched a program, an Innovation Focused Mentorship Project, in November 2016 which aims to increase the export power of Turkey with creativity, maintainability, innovation and high added value. The senior managements of the two cases at hand made decisions to initiate a Corporate Innovation System (CIS) Program. The CIS program has generated a repository of academics and assigned them to the organizations as mentors to guide the organizations in their innovation journey. The program offers a reference framework to all participating organizations, including Case Alpha and Beta.

\section{(i) Case Alpha}

Case Alpha organization operates in the service (travel and leisure) industry as one of the Europe's leading organizations and was awarded several times as the best of its vertical segment in recent years.

The organization includes two distinct endeavors at unit and corporate levels which invest in innovation; The digital innovation (DI) unit under IT where innovation is intensively practiced and corporate innovation (CI) directorate under Financial Assets. DI and CI are extensions of different lines/functions. They were established in January 2016. However, the origin of CI extends to 2007. It was established as Project Coordination Directorate in 2007, then incorporated R\&D function as well and evolved into its current state and renamed as CI in January 2016, following a managerial change. 
Case Alpha's digital innovation vision - to be a pioneer corporation utilizing technology - embraces three notions: innovative projects, open innovation approach and innovation culture. Innovative projects require discovering, testing and using disruptive technologies in customer experience. Open innovation necessitates collaborations with key players in local and global ecosystem. Innovation culture facilitates a start-up-like thinking and acting, co-development and massive resource utilization.

The organization operates in the travel and leisure industry that requires development of innovative products/services to obtain competitive advantage. DI unit focuses on researching key technologies/concepts such as Internet of Things (IoT), machine learning, wearable devices, robotics, virtual reality and augmented reality within the framework of open innovation, and developing digitized innovative solutions. The unit explores, evaluates, tests and implements technologies that create added value with the use of new technologies in the company and create a massive effect in customer experience. Within the framework of open innovation and collaboration principle, various collaborations with other institutions in the ecosystem such as techno cities, incubation centers and universities were started. The company provides an environment to conduct projects for the outsiders as well. These projects are given a chance to create demos using the facilities of the company such as labs. Thus, DI unit undertakes a bridging role for enterprises and institutions. In line with its aim, it cooperates with institutions in plug-and-play model which is a global innovation platform connecting startups to corporations.

DI unit involves six employees with diverse backgrounds (electric and electronic engineering, industrial engineering, programming and computer engineering).

The organization has completed one year in the TEA's program. DI has recently opened a developer portal (API portal) to attract the free lance developers offering digital services to access the organization.

The design of Corporate Innovation System at Case Alpha was a mission-critical goal for the Directorate and the assigned mentor. Once the CIS program was started in Case Alpha in December 2016, a mentor from a university was commissioned and teamed up with a director in the organization. Later on, this initiative evolved into a corporate innovation team to establish a reference model and to gain experience about all of its components. In the first month, an innovation assessment activity was conducted and produced a detailed plan showing weaknesses/strengths regarding innovation capacity, and an implementation roadmap.

\section{(ii) Case Beta}

The case organization is one of the leading ICT companies in Turkey and mainly serves financial organizations. In the last two years, with the help of a new senior management team the organization has gone through a transformation process embracing game changing technologies (e.g., Machine Learning, Big Data Analytics, IoT) and new software development practices (e.g., DevOps, Enterprise Agile Methods). The CIS Program was also part of such transformation program and sponsored by the CEO. 
When the CIS program was started in December 2016, it was the only official program entitled with innovation at the corporate level. Other innovation related efforts without any official label have existed in different units since the organization has strived for embracing new changes. Another point worth noting is that a digital innovation unit associated tightly with an innovation agenda was established before the CIS program was launched and had a focus on a special portfolio of digital products. As part of the transformation process, the organization has launched other process improvement initiatives. Due to the fact that its main competitors are financial institutes including banks, financial investment organizations, Case Beta has considerable achievements in applying international standards for operations and financial transactions.

The CIS Program at Case Beta showed a strong commitment to a systematic and integrated innovation model to be adopted for a long term. The CI was established as a unit in a separate premise at the heart of one of the most attractive entrepreneurship ecosystems in Turkey. The unit is led by a director and consists of seven dedicated employees with varying roles including a design thinking expert, specialists in business, technical architectures and communication, a specialist in user interface, and mobile developers.

\section{Findings}

In the two cases at hand, three strategic dimensions (type/focus, degree, and governance from the communication channels aspect) expressing structural characteristics (innovation endeavors, common framework, processes, and tools/techniques) were examined. The associations between strategic dimensions and structural characteristics, and the mediation of these associations were explored.

\subsection{Strategic dimensions underlying innovation alignment}

We derived three distinguishing dimensions from our empirical data to better understand innovation practices; innovation type, innovation degree, and governance from the communication aspect (openness).

\section{(i) Innovation type}

The innovation strategy of the CI unit at Case Alpha is driven by product and process innovation. The CIS program's expectation is to make prioritization of goals for yearly basis and determine choice of innovation types. Especially, in the first year of CI's establishment, the process innovation was a dominant choice due to business focus of the company.

The focus of DI unit at Case Alpha is on process-related innovation so that DI can assess promising solutions for the problems at hand. Process focus is essential to Case Alpha and contributes to possible value creation practices for whole customer life cycle. It is worth noting that DI acts as a facilitator to identify best matching between critical "pain points" perceived by key stakeholders and solution providers with expertise in the areas of data science and cloud-based solutions. 
The innovation strategy of the CI unit at Case Beta is driven primarily by product innovation. Similar to Case Alpha this was a strategic choice and the goal was to provide a systematic process, tools, and other means for innovation efforts to idea owners, entrepreneurs inside the organization. Since other units have already carried out innovation-related efforts, the DI unit at Case Beta determined to invest heavily in product-oriented innovation for the short and mid-term period.

The focus of DI unit at Case Beta is on product-related innovation in a particular solution domain. The DI unit was established before CI efforts were launched and was situated far from the premise of central CI. The DI team was a dedicated number of people isolated from the rest of organization. It had its own roadmap for a portfolio of digital products and has a mid-term plan (3-5 years) to establish a separate line of business.

(ii) Degree of innovation and governance

Degree of innovation and degree of openness are other distinguishing aspects for better understanding of innovation practice.

Since both corporate innovation units in Case Alpha and Case Beta have followed the common corporate model, they made an explicit choice about degree of innovation and degree of openness.

Regarding degree of innovation, interestingly enough in two cases, CIs decided to give a chance to radical as well as incremental innovation. Both organizations have already experienced incremental type of innovations but radical oriented practices have been new to the organizations.

The DI unit at Case Alpha appears to be incremental as the process-oriented innovation underlies the very logic of improvements and small changes on the service provided.

The DI unit at Case Beta was intended to be a game-changer and niche player in a specialized domain. This indicates that radical-oriented innovation was adopted as a strategic choice. In fact, the formation of DI was a sign of experimenting with a business model innovation.

From the governance point of view, regarding degree of openness, both CIs have determined to start with closed innovation in the short term and depending on the progress, they could go with openness whereby external partners could contribute to the CIS program. However, the CI at Case Alpha was aimed to give a trial for openness whatever the progress and in that sense Case Alpha was very determined to invest in collaborating with especially external partners that are already service providers. Indeed, in the second year of establishment of the CI at Case Alpha, there was an attempt to invite a number of service providers contributing to innovative solutions for problems encountered during customer journey. The CI at Case Beta tried openness for idea generation in a controlled manner. The collaborating partner has already built a formal relationship under the same parent company (Table 2).

\subsection{Structural characteristics}

Overall information about distinct innovation endeavors and innovation practices in corporate (CI) and unit (DI) levels in Case Alpha and Case Beta has already been 
Table 2. Analysis of three strategic dimensions in case alpha and case beta.

\begin{tabular}{llcc}
\hline & Type of (focus on) innovation & Degree of innovation & Governance \\
\hline Case Alpha & DI-Process oriented & DI-Incremental & DI-Closed, limited openness \\
& CI-Product and process & CI-Incremental & CI-Closed and significant \\
& oriented & and radical & attempt made for openness \\
Case Beta & DI-Product oriented, & DI-Radical & DI-Closed to internal units, \\
& business model, market & open to externals \\
& CI-Product oriented & CI-Incremental & CI-Closed and very limited \\
& & and radical & openness oriented \\
\hline
\end{tabular}

introduced in Case Study Background section. We elaborated additional information about structural arrangements in this section.

Both Case Alpha and Case Beta had similar structures in terms of an innovation context. Since the same CIS Program was initiated in both organizations, corporate innovation units have been sponsored by senior management and represented at the corporate level. DI units existed in both organizations and were structured independently from CI units. That is, CI and DI did not have any formal relationships and were not under the same senior management authority (Fig. 1). As the figure indicates, primary motivation behind established CI units was to coordinate and support all kinds of innovation efforts at the corporate level including DIs or other units. Both organizations have formally recognized Research and Development Centers, but do not have any joint efforts related to innovation. They mainly focus on research driven projects that can be supported by national and international funding agencies.

\section{(i) Reference model implemented}

The National Innovation Initiative in Turkey sponsored by Turkey Exporters Assembly has an ambitious goal to turn high potential manufacturing export firms into innovation driven world-class organizations. The reference innovation framework has been used in two cases. The framework has some similarity with IMProve model, a European Innovation Management platform [Meissner et al. (2008)]. The framework includes a number of components such as strategy (including corporate and

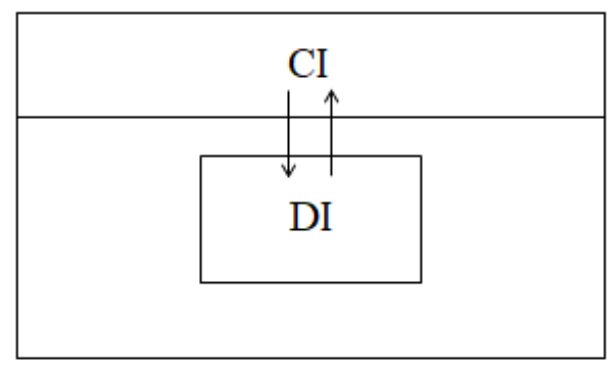

Case Alpha

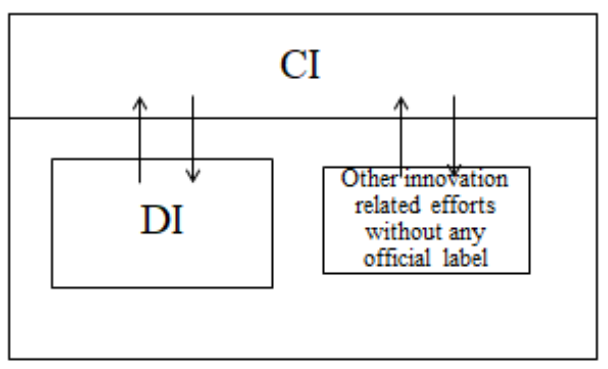

Case Beta

Fig. 1. Structural arrangements in terms of innovation context. 
technology roadmap), governance (organizational arrangements, principles, decision making), process (roles, activities, tools, techniques), culture and communication, measurement and performance, sustainability. However, the reference innovation framework has been built promoted to address the need for an innovation system tailored to specific needs of an organization. That is, the framework does not provide any a priori roadmap on how to design a CIS for an organization rather it strongly encourages to determine organization-specific CIS by leveraging mentors' and leading actors' experience in an organization.

\section{(ii) Digital innovation process of case alpha}

The DI unit manages the digital innovation process as seen in Table 3. The unit primarily focuses on the first phase Discovery that includes efforts regarding market and sector research, competitive analysis, technology and trend analysis, customer experience and needs analysis, generating and verifying business ideas. Second phase is Development. The organization develops joint projects with enterprises, technocities and incubation centers that support start-up ecosystem. The third phase is Testing that includes Proof of Concept $(\mathrm{PoC})$ by which the organization tests the product's usefulness. After that a pilot study is applied in some experimental (trial) work areas for 3 months in order to see the problems encountered by employees using the product/service with new features. Afterwards testing is performed with the real customers. Before the product is applied in all work areas, it is tested by a few sample work units for its convenience and efficiency. If these limited tests receive positive feedback, the product is distributed to all work units. After feasibility studies with relevant departments, commercializing phase starts. Normally, the DI unit is not in charge of that phase. The employees of Customer Solutions and Operational Solutions sub-function are the actual product developers. However, since the unit is one-andhalf years old, roles and responsibilities are not clearly defined and executed. There are some occasions where the unit cannot handover/transfer the work/responsibility to other business units and they inevitably carry on the process of commercializing.

Table 3. Digital innovation process unfolds.

\begin{tabular}{|c|c|c|c|c|}
\hline Discover & Develop & Test & Evaluate & Commercialize \\
\hline $\begin{array}{l}\text { Market and } \\
\text { sector research }\end{array}$ & $\begin{array}{l}\text { Prototyping } \\
\text { (In-house product } \\
\text { development) }\end{array}$ & $\begin{array}{l}\text { PoC (Proof of } \\
\text { Concept) and } \\
\text { Demo }\end{array}$ & $\begin{array}{l}\text { Analysis of test } \\
\text { and pilot } \\
\text { studies }\end{array}$ & $\begin{array}{l}\text { Purchase of } \\
\text { product/ } \\
\text { service }\end{array}$ \\
\hline $\begin{array}{l}\text { Competitive } \\
\text { analysis }\end{array}$ & $\begin{array}{l}\text { Cooperative project } \\
\text { development with } \\
\text { enterprises }\end{array}$ & Pilot studies & $\begin{array}{l}\text { Feasibility } \\
\text { studies with } \\
\text { business units }\end{array}$ & Contracting \\
\hline $\begin{array}{l}\text { Technology and } \\
\text { trend analysis }\end{array}$ & $\begin{array}{l}\text { Cooperative } \\
\text { project } \\
\text { development } \\
\text { with academics }\end{array}$ & $\begin{array}{l}\text { Testing with } \\
\text { actual customers }\end{array}$ & & $\begin{array}{l}\text { Commercial } \\
\text { initiation } \\
\text { of service }\end{array}$ \\
\hline $\begin{array}{l}\text { Customer experience } \\
\text { and needs analysis } \\
\text { Idea generation } \\
\text { and verification }\end{array}$ & & & & \\
\hline
\end{tabular}


Table 4. Corporate innovation process of case beta.

\begin{tabular}{llll}
\hline Exploration & Portfolio backlog & Selection & Product development \\
\hline Analysis of inputs & $\begin{array}{l}\text { List of tasks or } \\
\text { project candidates } \\
\text { from sources: }\end{array}$ & Prioritization & Ideation \\
$\begin{array}{l}\text { Problems } \\
\text { Technologies }\end{array}$ & graphs/charts & $\begin{array}{l}\text { Lean Business } \\
\text { Model Canvas }\end{array}$ & $\begin{array}{l}\text { PoC concept clarification } \\
\text { Customer Journey Map }\end{array}$ \\
$\begin{array}{l}\text { Ideas } \\
\text { Products }\end{array}$ & & Conversion \\
Macro trends & & PoC/demo/prototype \\
Insights & & Diffusion \\
Technology roadmap & & & \\
\hline
\end{tabular}

The director of DI unit states the situation as follows: "We are more like a supportive function in the organization. We are research and development group, not a solution group".

Ideally, the unit discovers the solution and hands the project then to the relevant unit to let it develop applications.

(iii) Corporate innovation process of case beta

The process which is handled as seen in Table 4, exhibits several major characteristics: It is customer oriented, its outcome is proof of concept (PoC) demo or prototypes, it focuses on both problems and solutions, a diverse team including business and technical people develops the product, $\mathrm{PoC} /$ demo is developed in 1 to 2 months, and the process is owned by CI.

The framework is iterative in nature and includes four phases; Exploration, Portfolio Backlog, Selection and Product Development. Exploration phase grasps and analyzes the input from various sources (problems, technologies, ideas, products, macro trends and insights). As a result of the analysis, a report (technology roadmap) is generated and shared with relevant stakeholders so that value adding products for customers are involved in the portfolio. Value adding products are selected referring to a set of criteria. Portfolio Backlog is constituted with list of tasks or project candidates. Selection prioritizes the items selected from the backlog referring to predetermined criteria set and comparison graphs/charts. Lean Business Model Canvas is created for the selected item/product. Product development consists of ideation, conversion and diffusion stages. In ideation, using design thinking methodology, $\mathrm{PoC}$ concept is clarified and Customer Journey Map is generated. Conversion stage enables the innovation team to develop solutions relevant to the $\mathrm{PoC}$ concept. An approval is received from relevant stakeholders. In diffusion stage, approved $\mathrm{PoC}$ is handed over to product teams for development.

\section{(iv) Tools/techniques}

Two cases at hand use lean start-up methodology's minimum viable product (MVP) practice and proof of concept (PoC) for product development [Ries (2011); Martinez 
(2016)] and a number of typical collaboration, communication, productivity and project management tools, and enterprise idea management software [Vandenbosch et al. (2006); Westerski et al. (2011); Xie and Zhang (2010)]. MVP is a product having enough features to allow useful feedback from early adopters. MVP and PoC are primarily utilized as a means to accelerate the process and to get some results to proceed further for fast, iterative and incremental product development. In this manner, lean start-up methodology avoids waste, in terms of both time and money.

Case Alpha uses Slack (for communication and collaboration), Trello and Jira (for project management), Crunch Base (a global information hub to follow investors and utilize start up projects), Google Drive, spreadsheets, lean product development methodology and Enterprise Idea Management Software.

Case Beta uses Slack (for communication and collaboration), Kanban Boards on Taiga.io (for project management), Workplace (an enterprise social media platform), IdeaScale (cloud-based innovation software platform for competition), Google Drive, spreadsheets, lean product development methodology, Enterprise Idea Management Software, Design Thinking and Agile methods.

We provided further information about Enterprise Idea Management Software that is used by Case Alpha below.

The organization has been using the idea management software which was purchased from a vendor three months before our examination. Every employee has a right to recommend an idea to the business unit where he/she works. The organization focuses on recommendations that embrace ideas regarding new technology (i.e. eye scan), low-cost, efficiency and effectiveness in the resource usage, waste elimination, process improvements, safety and security and ergonomics.

The business unit (BU) managers track the evaluation and implementation status of the recommendations of each quarter. It is mandatory that the system is monitored at the managerial level. The number of open, closed and implemented recommendations on the basis of the business unit's annual target is monitored by the BU managers. After project approvals, detailed planning starts and needs to be completed within 90 days. Monthly and yearly status reports are prepared by CI and shared with the senior management.

In order to encourage employees for idea recommendation, a reward mechanism is executed quarterly by CI, as well.

\section{Discussion}

Regarding the structural characteristic related findings of Case Alpha and Case Beta, we delineated the existence of similar structures that were identified as corporate, digital, and other innovation practices. Due to the reference framework adopted, it is not surprising to see that in both organizations the CI efforts are sponsored by senior management and are based upon a number of explicit decision points including focus, degree and governance of innovation. Another similarity was found to be related to governance (openness vs closeness) and degree of innovation.

The findings suggest that strategic dimensions which characterize innovation practices at corporate and unit levels form the underpinnings of an innovation 
alignment issue. In particular, regarding the degree of openness, boundary spanning for innovation remains under the control of organizational authority, which at best provides limited openness for communicating and exchanging ideas with actors outside the controlled boundaries. We agree with Lavie et al. [2006] that innovation alignment needs to be extended from an intra-organizational setting to interorganizational or community settings and there needs to be structural ambidexterity. Moreover, such an understanding supports Carayannis and Campbell's [2011] work in which different knowledge and innovation modes are combined and integrated via coexisting, co-evolving, co-specializing and co-opeting diverse and heterogeneous configurations of knowledge creation, diffusion and use in an emerging fractal knowledge and innovation ecosystem.

The idea of openness in innovation contexts for both organizations is a controversial issue given the structural constraints perceived by key actors including the innovation director and senior manager. This suggests the need to observe the associations between strategic dimensions and structural characteristics. As an open research matter, one needs to further delineate the effects of actors' perceptions of and commitment to aligning innovation efforts. This calls for research to examine leadership issues rather than structural issues [O'Reilly and Tushman (2011)].

Regarding the degree of innovation, incremental innovation is well-recieved in both cases. Both cases experience radical innovation as a new experience. DIs in the two cases differ in that they do not have any dependency on CIs. In fact, as one may expect, we observed that digital innovation and other innovation practices have different characteristics in the case organizations. This means that independent innovation endeavors having their own goals, boundaries, structures and processes have co-evolved as a conscious choice or as an unintentionally misaligned practice. The former is a strategic choice and may be associated with an innovation diffusion leadership style. The latter may be associated with pragmatic matters and structural complexity driven innovation alignment.

The DI's attempt in Case Alpha (opening API portal to attract free lance developers) complies with adopting a crowd-based innovation strategy which is suggested to improve incremental innovations [Greco et al. (2016)]. On the other hand, the DI in Case Beta focus on radical innovation which necessitates a collaborative or network based innovation strategy [Greco et al. (2016)].

The focus of innovation appears to be an essential aspect to characterize innovation practices at Case Alpha and Case Beta. The findings suggest that product innovation, business model and market innovation are clear choices for the DI in Case Beta whereas product innovation is the main focus for the CI in Case Beta. Since the CI and DI at Case Alpha have different choices of innovation type, managerial agenda, structures, and processes are different. On the other hand, this is not the same for the CI and DI at Case Beta. We argue that the difference could be due to the strategizing acts based on the degree of uncertainty and instability that the organization encounters.

Our interpretation of the evidence suggests that strategizing act as a high-level notion has an explanatory power to articulate the associations between strategic dimensions and structural characteristics. That is, the degree of uncertainty and 
instability show us four possible zones as suggested by Bessant et al. [2005]. The "exploit" zone corresponds to low uncertainty and low instability. The "uncover" zone corresponds to high uncertainty but low instability. The "flex" zone corresponds to low uncertainty but high instability. Lastly, the "co-evolve" zone corresponds to high uncertainty and high instability. It appears that for CI at Case Alpha the "exploit" zone (all kinds of ideas bringing process improvements) and the "uncover" zone (customer journey) describe strategizing acts. It appears that for DI at Case Alpha the "exploit" zone (digital user experience) and "uncover" zone (API portal for software developer ecosystem) describe strategizing acts. On the other hand, for DI at Case Beta, the "co-evolve" (new product, new market and new business model) zone is the signature of a strategizing act. For CI at Case Beta we observe the very idea of ambidexterity for which four strategizing acts have been utilized. These are "exploit" (focusing on IT supported core process improvements), "uncover" (core domain knowledge transferred into new industry and market), "flex" (core domain knowledge transferred into new technology shifts with changing rules of game), and "co-evolve" (innovation efforts in search of new products, new markets and new business models).

These co-evolved innovation practices may be aligned or misaligned depending on their own innovation development trajectory. We contend that those aspects which characterize innovation practice can be used as signs to determine degree of alignment. The managerial implications of the degree of innovation alignment may be associated with the achievement of sustainable innovation in organizations. At one extreme senior management should be aware that when the degree of alignment is extremely weak this could mean it is totally misaligned. This can enable competitive efforts, but there is a high possibility that it may turn into cannibalized innovation efforts. As the time progressed Case Beta gave some signs of the cost of misalignment as a number of cross boundary innovation issues rose on the senior management agenda. The other extreme could be an extremely high degree of innovation alignment that leads to ideal collaboration between all innovation efforts in terms of structure, process and techniques. Another future research issue could be to articulate the managerial implications of the degree of alignment.

It appears that DI and CI at Case Alpha operate in steady state environment with stable rules of game (see the "exploit" zone in Fig. 2) [Bessant et al. (2005)], and performs incremental process innovation in a mature market. Furthermore, DI and CI at Case Alpha operate in stable environment in terms of rules of game, even if the state of knowledge is less clear (see the "uncover" zone in Fig. 2). In such a case, new knowledge is needed to find out at exploring around technological or market trajectories, although there is still an established market or product technology, the challenge is to uncover via strategic and targeted research [Bessant et al. (2005)]. In the course of innovation, ideation is the most critical step in fulfilling these strategic and research needs. This fulfillment can be better articulated by the concept of ideation portfolio management [Heising (2012)].

On the other hand, CI in Case Beta operates in all combinations of various degrees of uncertainty and instability. That is, in four of the zones, Case Beta carried out various attempts. For instance, incremental process innovation in mature 


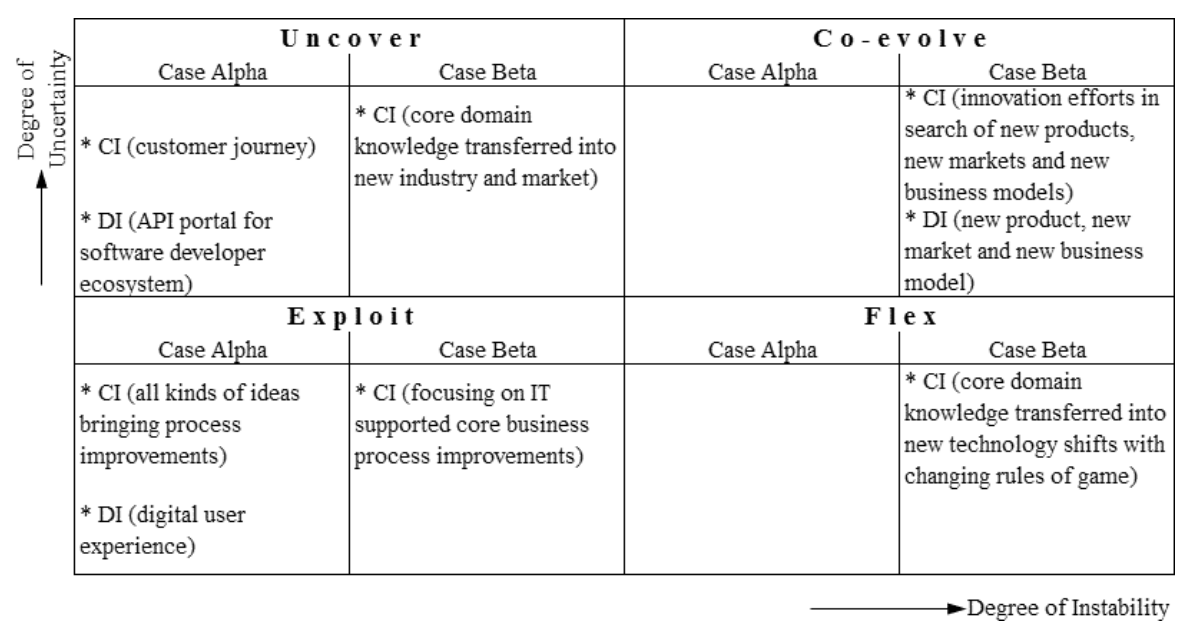

Source: Adopted from Bessant et al. [2005].

Fig. 2. Characterizing innovation practices based on the integrated framework.

market (see the "exploit" zone in Fig. 2), and core domain knowledge transferred into new industry and market (see the 'uncover' zone in Fig. 2). Moreover, CI in Case Beta operates in an environment where rules of game change but there is high degree of knowledge about these shifts or how to find out and respond [Bessant et al. (2005)]. That is, core domain knowledge transferred into new technology shifts with changing rules of game (see the "flex" zone in Fig. 2). One can argue that, DI and CI in Case Beta exist in an environment where rules of game shifts and they do not know and they do not know how to know [Bessant et al. (2005)]. Initiatives at CI of Case Beta can be positioned at ideation or MVP stages of the innovation process. Thus, one can argue that these initiatives are at early stages of innovation projects whereas in DI innovation efforts are towards the later stages of innovation process.

We argue that the cases at hand demonstrate various strategizing acts as a portfolio of experiments to understand and manage degree of uncertainty and degree of instability conditioning innovation practices. These acts appear to be a conscious choice at the strategic level and leverage structural ambidexterity. The strength of Case Beta is the ability to experiment with all possible strategizing acts (four zones in Fig. 2), structural ambidexterity, and strategic dimensions as well. Whereas Case Alpha seems to make control experiments related to a certain type of strategic acts and dimensions. The findings also suggest that both cases signify the higher the degree of uncertainty and stability, the higher the degree of innovation (that is, radical innovation) and degree of openness [Bessant et al. (2005)].

\section{Conclusion}

Innovation requires a unique approach that emphasizes the fact that for organizations change is inevitable and that technology should be considered an effective aid. Essentially, innovation practice still needs time to prove its real value. Both 
researchers and field experts strive to better understand the innovation practices of organizations. In this research we focus on how this effort may be better examined, particularly regarding the strategic and structural aspects of different innovation efforts in organizations. One of the most critical issues in this context is to ensure that these different innovation efforts can achieve a successful outcome through alignment. The strategic and structural configurations of the organization will bring about different strategizing options. In this research, we have stated that an integrated framework is needed to better understand innovation alignment. The integrated framework utilizing three high-level notions (strategic dimensions, structural characteristics, strategizing acts) and related conceptual components that we put forward to meet this need has been deployed in these two cases.

First of all, regarding the first high-level notion, in both cases the strategic dimensions of different innovation practices showed similarities. Although the common innovation reference model was implemented for both organizations, it was seen that the innovation focus was mostly on the product in one case and on the product and process in the other case. On the other hand, the similarities were seen in both cases with respect to degree of innovation: partially radical and predominantly incremental. As for the governance model, initially the innovation efforts were closed to outsiders, but as the time progress the need for open innovation was emerged. We found that both cases differ with respect to embracing business model innovation and new market innovation models. We demonstrate that strategic dimensions have explanatory power to investigate the innovation alignment in these two cases.

Secondly, regarding the second high-level notion, although different tools are used in both cases, we have seen that similar toolboxes which meet the various requirements of the digital innovation process were used at the unit and corporate levels. In both of these cases, it was seen that idea management systems were especially given importance for internal use. Therefore, we can say that structure (organizational arrangement/configuration) for innovation (DI, CI), toolboxes and processes are related to strategic dimensions. This research clearly reveals the association between strategic dimensions and structural characteristics in the context of innovation alignment. We have observed that the closed, incremental and process-oriented innovation strategy is particularly associated with innovation efforts at corporate level. We have seen that an organization that chooses a radical, product-oriented, and partially open innovation strategy is associated with a more exclusive innovation structure.

Lastly, the strategizing act is the third high-level notion that better reveals the association between strategic dimensions and structural characteristics. With the help of third high-level notion, four different strategizing acts were examined to sustainable alignment of innovation practices in an organization. That is, the degree of uncertainty and instability show us four possible zones/strategizing acts (exploit, uncover, flex, co-evolve) in the cases examined. Interestingly, in an organization these four zones can be seen together and manifest themselves in different structures. What is even more interesting to note is that these structures are independent of each other even though their paths sometimes intersect and over time frictions even 
may arise. It is therefore vital for the manager to decide which strategic dimensions can best be associated with which structural characteristics and how to make this choice. This study is shaping new research problems and the managerial agenda by contributing both to conceptual and practical issues.

\section{References}

Abernathy, W. J. and Utterback, J. M. (1978). Patterns of industrial innovation. Technology Review, 80, 7: 40-47.

Avital, M. and Te'Eni, D. (2009). From generative fit to generative capacity: Exploring an emerging dimension of information systems design and task performance. Information Systems Journal, 19, 4: 345-367.

Bailey, D. E., Leonardi, P. M. and Barley, S. R. (2012). The lure of the virtual. Organization Science, 23: 1485-1504.

Bantel, K. A. and Jackson, S. E. (1989). Top management and innovations in banking: Does the composition of the top team make a difference? Strategic Management Journal, 10, S1: $107-124$.

Barrett, M., Oborn, E., Orlikowski, W. J. and Yates, J. (2012). Reconfiguring boundary relations: Robotic innovations in pharmacy work. Organization Science, 23, 5: 1448-1466.

Bessant, J., Lamming, R., Noke, H. and Phillips, W. (2005). Managing innovation beyond the steady state. Technovation, 25(12): 1366-1376.

Bessant, J. and Tidd, J. (2007). Innovation and Entrepreneurship. John Wiley \& Sons. Boer, H. and During, W. E. (2001). Innovation, what innovation? A comparison between product, process and organisational innovation. International Journal of Technology Management, 22, 1-3: 83-107.

Campbell, D. F. and Guttel, W. H. (2005). Knowledge production of firms: Research networks and the "scientification" of business R\&D. International Journal of Technology Management, 31, 1-2: 152-175.

Carayannis, E. G. and Campbell, D. F. (2006). Mode 3": Meaning and implications from a knowledge systems perspective. Knowledge Creation, Diffusion, and Use in Innovation Networks and Knowledge Clusters. A Comparative Systems Approach Across the United States, Europe and Asia, pp. 1-25.

Carayannis, E. G. and Campbell, D. F. (2009). 'Mode 3' and 'Quadruple Helix': Toward a 21st century fractal innovation ecosystem. International Journal of Technology Management, 46, 3-4: 201-234.

Carayannis, E. G. and Campbell, D. F. (2011). Open innovation diplomacy and a 21st century fractal research, education and innovation (FREIE) ecosystem: Building on the quadruple and quintuple helix innovation concepts and the "mode 3" knowledge production system. Journal of the Knowledge Economy, 2, 3: 327.

Chandler, A. D. (1990). Strategy and Structure: Chapters in the History of the Industrial Enterprise, Vol. 120. MIT Press.

Cheng, C. C. and Huizingh, E. K. (2014). When is open innovation beneficial? The role of strategic orientation. Journal of Product Innovation Management, 31, 6: 1235-1253.

Chesbrough, H. W. (2006). Open Innovation: The New Imperative for Creating and Profiting from Technology. Harvard Business Press.

Child, J. (1972). Organizational structure, environment and performance: The role of strategic choice. Sociology, 6, 1: 1-22.

Cooper, J. R. (1998). A multidimensional approach to the adoption of innovation. Management Decision, 36, 8: 493-502.

Cottam, A., Ensor, J. and Band, C. (2001). A benchmark study of strategic commitment to innovation. European Journal of Innovation Management, 4, 2: 88-94. 
Damanpour, F. (1987). The adoption of technological, administrative and ancillary innovations: Impact of organizational factors. Journal of Management, 13, 4: 675-688.

Damanpour, F. (1991). Organizational innovation: A meta-analysis of effects of determinants and moderators. Academy of Management Journal, 34, 3: 555-590.

Dewar, R. D. and Dutton, J. E. (1986). The adoption of radical and incremental innovations: An empirical analysis. Management Science, 32, 11: 1422-1433.

Dilan, E. and Aydin, M. (2016). The drivers and implications of information system process innovations: A financial services case study. Yönetim Bilişim Sistemleri Dergisi, 1, 3: 118-128.

Duening, T. N. (2007). Enterprise process innovation - The ingredients are well known, but what is the recipe? International Journal of Innovation and Technology Management, $\mathbf{4}, 1$ : $87-101$.

Dursun, M. E., O'Connell, J. F., Lei, Z. and Warnock-Smith, D. (2014). The transformation of a legacy carrier: A case study of Turkish Airlines. Journal of Air Transport Management, 40: 106-118, doi: 10.1016/j.jairtraman.2014.06.003.

Etzkowitz, H. and Leydesdorff, L. (2000). The dynamics of innovation: From National Systems and "Mode 2" to a Triple Helix of university-industry-government relations. Research Policy, 29, 2: 109-123.

Felin, T. and Zenger, T. R. (2014). Closed or open innovation? Problem solving and the governance choice. Research Policy, 43, 5: 914-925.

Francis, D. and Bessant, J. (2005). Targeting innovation and implications for capability development. Technovation, 25, 3: 171-183.

Gao, L. S. and Iyer, B. (2006). Analyzing complementarities using software stacks for software industry acquisitions. Journal of Management Information Systems, 23, 2: 119-147.

Garcia, R. and Calantone, R. (2002). A critical look at technological innovation typology and innovativeness terminology: A literature review. Journal of Product Innovation Management: An International Publication of the Product Development $\&$ Management Association, 19, 2: 110-132.

Greco, M., Grimaldi, M. and Cricelli, L. (2016). An analysis of the open innovation effect on firm performance. European Management Journal, 34, 5: 501-516.

Greenwood, R. and Hinings, C. R. (1993). Understanding strategic change: The contribution of archetypes. Academy of Management Journal.

Heising, W. (2012). The integration of ideation and project portfolio management - A key factor for sustainable success. International Journal of Project Management, 30, 5: 582-595.

Henderson, R. M. and Clark, K. B. (1990). Architectural innovation: The reconfiguration of existing product technologies and the failure of established firms. Administrative Science Quarterly, 9-30.

Hovgaard, A. and Hansen, E. (2004). Innovativeness in the forest products industry. Forest Products Journal, 54, 1.

Isaksson, V. and Hylving, L. (2017). The Effect of Anarchistic Actions in Digital Product Innovation Networks: The Case of "Over the Air" Software Updates.

Johannessen, J. A., Olsen, B. and Lumpkin, G. T. (2001). Innovation as newness: What is new, how new, and new to whom? European Journal of Innovation Management, 4, 1: 20-31.

Jonsson, K., Westergren, U. H. and Holmström, J. (2008). Technologies for value creation: An exploration of remote diagnostics systems in the manufacturing industry. Information Systems Journal, 18, 3: 227-245.

Knight, K. E. (1967). A descriptive model of the intra-firm innovation process. The Journal of Business, 40, 4: 478-496.

Lavie, D., Kang, J. and Rosenkopf, L. (2011). Balance within and across domains: The performance implications of exploration and exploitation in alliances. Organization Science, 22, 6: 1517-1538.

Lazzarotti, V., Bengtsson, L., Manzini, R., Pellegrini, L. and Rippa, P. (2017). Openness and innovation performance: An empirical analysis of openness determinants and performance mediators. European Journal of Innovation Management, 20, 3: 463-492. 
Lee, J. and Berente, N. (2012). Digital innovation and the division of innovative labor: Digital controls in the automotive industry. Organization Science, 23, 5: 1428-1447.

Lyytinen, K., Yoo, Y. and Boland, R. J., Jr., (2016). Digital product innovation within four classes of innovation networks. Information Systems Journal, 26, 1: 47-75.

Martinez, M. S. (2016). Good Practices of the Lean Startup Methodology: Benefits, Challenges and Recommendations.

Matthyssens, P., Vandenbempt, K. and Berghman, L. (2006). Value innovation in business markets: Breaking the industry recipe. Industrial Marketing Management, 35, 6: 751-761.

Meissner, J. O., Brunswicker, S., Schweikert, S. and Wolf, P. (2008, June). Scaffolding innovations: Implications of regional innovation barriers for platform-based innovation management improvement. In Technology Management Conference (ICE), 2008 IEEE International, IEEE, pp. 1-10.

Milling, P. M. and Stumpfe, J. (2000). Product and process innovation: A system dynamicsbased analysis of the interdependencies. In 18th International Conference of the System Dynamics Society Sustainability in the Third Millennium, Bergen, Norway.

Mustonen-Ollila, E. and Lyytinen, K. (2004). How organizations adopt information system process innovations: A longitudinal analysis. European Journal of Information Systems, 13, 1: 35-51.

Nambisan, S., Lyytinen, K., Majchrzak, A. and Song, M. (2017). Digital innovation management: Reinventing innovation management research in a digital world. MIS Quarterly, $41,1$.

Nalebuff, B. J., Brandenburger, A. and Maulana, A. (1996). Co-Opetition. Harper Collins Business, London.

Nylén, D. and Holmström, J. (2015). Digital innovation strategy: A framework for diagnosing and improving digital product and service innovation. Business Horizons, 58, 1: 57-67.

Oke, A., Burke, G. and Myers, A. (2007). Innovation types \& performance in growing UK SMEs. International Journal of Operations and Production Management, 27, 7: 735-753.

O'Reilly III, C. A. and Tushman, M. L. (2008). Ambidexterity as a dynamic capability: Resolving the innovator's dilemma. Research in Organizational Behavior, 28: 185-206.

O'Reilly III, C. A. and Tushman, M. L. (2011). Organizational ambidexterity in action: How managers explore and exploit. California Management Review, 53, 4: 5-22.

Powell, W. W. and DiMaggio, P. J. (1991). The New Institutionalism in Organizational Analysis, University of Chicago Press, Chicago.

Ries, E. (2011). The Lean Startup, Vol. 1. Crown Business, New York.

Ritala, P. and Hurmelinna Laukkanen, P. (2013). Incremental and radical innovation in coopetition - The role of absorptive capacity and appropriability. Journal of Product Innovation Management, 30, 1: 154-169.

Rowley, J., Baregheh, A. and Sambrook, S. (2011). Towards an innovation-type mapping tool. Management Decision, 49, 1: 73-86.

Saebi, T. and Foss, N. J. (2015). Business models for open innovation: Matching heterogeneous open innovation strategies with business model dimensions. European Management Journal, 33, 3: 201-213.

Schilling, M. A. (2015). Technology shocks, technological collaboration and innovation outcomes. Organization Science, 26, 3: 668-686.

Svahn, F., Mathiassen, L. and Lindgren, R. (2017). Embracing digital innovation in incumbent firms: how Volvo cars managed competing concerns. Mis Quarterly, 41, 1.

Swanson, E. B. (1994). Information systems innovation among organizations. Management Science, 40, 9: 1069-1092.

Thangamani, G. (2016). Modified approach to risk assessment - a case study on product innovation and development value chain. International Journal of Innovation, Management and Technology, 7, 1: 16.

Tidd, J. (1993). Technological innovation, organizational linkages and strategic degrees of freedom. Technology Analysis \& Strategic Management, 5, 3: 273-284. 
Tidd, J. (1997). Complexity, networks \& learning: Integrative themes for research on innovation management. International Journal of Innovation Management, 1, 1: 1-21.

Tidd, J. (2001). Innovation management in context: Environment, organization and performance. International Journal of Management Reviews, 3, 3: 169-183.

Tidd, J., Bessant, J. and Pavitt, K. (2005). Managing Innovation Integrating Technological, Market and Organizational Change. John Wiley and Sons Ltd.

Tiwana, A., Konsynski, B. and Bush, A. A. (2010). Research commentary - Platform evolution: Coevolution of platform architecture, governance, and environmental dynamics. Information Systems Research, 21, 4: 675-687.

Trott, P. (2005). Innovation Management and New Product Development. Prentice-Hall, Harlow.

Tuomi, I. (2002). Networks of Innovation. Oxford University Press, Oxford.

Tushman, M. L. and O'Reilly III, C. A. (1996). Ambidextrous organizations: Managing evolutionary and revolutionary change. California Management Review, 38, 4: 8-29.

Utterback, J. M. (1971). The process of technological innovation within the firm. Academy of Management Journal, 14, 1: 75-88.

Van de Ven, A. H., Polley, D. E., Garud, R. and Venkataraman, S. (1999). The innovation journey.

Vandenbosch, B., Saatcioglu, A. and Fay, S. (2006). Idea management: A systemic view. Journal of Management Studies, 43, 2: 259-288.

Velamuri, V. K., Neyer, A. and Möslein, K. M. (2008). What influences the design of hybrid products? Lessons learned from the preventive health - care industry. In Proceedings of the 15th International Product Development Management Conference, Hamburg.

Westerski, A., Iglesias, C. A. and Nagle, T. (2011). The road from community ideas to organizational innovation: A life cycle survey of idea management systems. International Journal of Web Based Communities, 7, 4: 493-506.

Xie, L. and Zhang, P. (2010). Idea management system for team creation. JSW, 5, 11: 1187-1194.

Yin, R. K. (2013). Case Study Research: Design and Methods. Sage Publications.

Yoo, Y., Boland, R. J., Jr., Lyytinen, K. and Majchrzak, A. (2012). Organizing for innovation in the digitized world. Organization Science, 23, 5: 1398-1408.

Yoo, Y., Henfridsson, O. and Lyytinen, K. (2010). Research commentary - the new organizing logic of digital innovation: An agenda for information systems research. Information Systems Research, 21, 4: 724-735.

\section{Appendix A. Interview Details}

\begin{tabular}{llll}
\hline $\begin{array}{l}\text { Number of } \\
\text { lnterviews }\end{array}$ & Interviewee & Interview date & Interview place \\
\hline 2 & Director of DI unit (Case Alpha) & $27 / 01 / 2017,10 / 03 / 2017$ & Directorate \\
2 & Director of DI unit (Case Beta) & $24 / 03 / 2017,21 / 04 / 2017$ & Directorate \\
3 & Innovation Mentor (Case Alpha) & $03 / 02 / 2017,03 / 03 / 2017$, & Mentor's office \\
& & $28 / 04 / 2017$ & Mentor's office \\
3 & Innovation Mentor (Case Beta) & $05 / 05 / 2017,16 / 06 / 2017$, & Directorate \\
& & $15 / 09 / 2017$ & Directorate \\
4 & Specialist of DI unit (Case Alpha) & $17 / 02 / 2017,07 / 04 / 2017$ & \\
& Specialist of DI unit (Case Beta) & $14 / 04 / 2017,12 / 05 / 2017$, & \\
& & $02 / 06 / 2017,23 / 06 / 2017$ & \\
\hline
\end{tabular}




\section{Biography}

Ebru Dilan, a lecturer of Management Information Systems (MIS), Faculty of Management at the Kadir Has University, since 2012. Her special focus is on Project Management, Innovation Management, Corporate Innovation Systems, Software Development Methods \& Techniques, Agile Approaches, Design Thinking and Education Technologies. Before joining to Kadir Has University, she worked as instructor at Bilkent University, School of Applied Technology and Management, Department of Business Information Management between 1997 and 2012. During her 15 years of tenure with Bilkent University, she received "The Distinguished Teacher for the Year 2010 Award". She is qualified for visiting Haaga-Helia University of Applied Sciences, Helsinki, Finland for the framework of ErasmusTeaching Staff Mobility in year 2010. Before joining to Bilkent University, she had worked in the industry as a technical expert between 1993 and 1997. She has BSc degree of Geological Engineering from Hacettepe University in 1993; MBA degree from Atılım University in 2007.

Mehmet N. Aydin, as Associate Professor of MIS and Assoc. Dean at Faculty of Management and the Director of iNEO Innovation and Entrepreneurship Technology Transfer Office at Kadir Has University, has provided organizations with proven expertise in the emerging field of cloud computing, Agile Project Management, Corporate Innovations Systems and Technology Management, Network Science. He holds PhD in MIS from University of Twente, The Netherlands. Dr. Aydin worked at the Institute for Innovation and Technology Management, Ryerson University, Toronto, Canada and at the Department of Information Systems and Change Management at University of Twente, the Netherlands. He has published over 50 articles as journal papers (e.g., Journal of Database Management, Information Frontiers, International Journal of Information Technology Project Management (IJITPM), Journal of Enterprise Management), book chapters (e.g., Springer series on Lecture Notes in Computer Science) conference proceedings (IFIP 8.1, CAISE). His contribution to the research field of method engineering is laudable and cited in various studies. 